\title{
Gene Expression Profiling of Lung Myofibroblasts Reveals the Anti-Fibrotic Effects of Cyclosporine
}

\author{
Nao Hirota, ${ }^{1}$ Takafumi Ito, ${ }^{1}$ Shuichi Miyazaki, ${ }^{2}$ Masahito Ebina ${ }^{3}$ and \\ Sakae Homma ${ }^{1}$ \\ ${ }^{1}$ Department of Respiratory Medicine, Toho University Omori Medical Center, Tokyo, Japan \\ ${ }^{2}$ Division of Microbiology and Immunology, The Center for Advance Research Graduate \\ School of Medical Science, Toho University Medical Center, Tokyo, Japan \\ ${ }^{3}$ Pulmonary Center, Tohoku Pharmaceutical University Hospital, Sendai, Miyagi, Japan
}

\begin{abstract}
Cyclosporine, a calcineurin inhibitor, is a potent immunosuppressive agent that acts chiefly through the inactivation of T-lymphocytes. Several clinical studies have demonstrated the effectiveness of cyclosporine for treating fibrotic lung disease, but the underlying mechanism remains elusive. We hypothesized that cyclosporine exerts direct effects against fibrogenesis of lung myofibroblasts, and aimed to elucidate the mechanism of this anti-fibrotic effect through gene-expression profiling using DNA microarray analysis. We found that cyclosporine suppressed the expression of alpha-smooth muscle actin and collagen type I in myofibroblasts that had been differentiated from a fetal human lung fibroblast cell line by induction with transforming growth factor (TGF)- $\beta$. Furthermore, microarray analysis revealed that cyclosporine downregulated 57 genes whose expression levels were increased by TGF- $\beta$, and up-regulated 73 genes, whose expression was decreased by TGF- $\beta$. Classifying these 57 down-regulated and 73 up-regulated genes with the Database for Annotation, Visualization and Integrated Discovery (DAVID) web tool, we have identified the involvement of several functional categories, including innate immunity, cytokine interaction, growth factor, and cancer pathway. Of the identified genes, we selected three fibrosis-related genes, insulin-like growth factor binding protein 2 (IGFBP2), inhibitor of DNA binding 1 (ID1) and peroxisome proliferator-activated receptor gamma (PPARG), and validated their expression patterns by quantitative reverse transcription-polymerase chain reaction. Cyclosporine treatment decreased the expression levels of IGFBP2 and ID1, but increased PPARG expression. These results suggest that cyclosporine is a potent anti-fibrotic agent acting on myofibroblasts. Therefore, cyclosporine shows potential as a novel remedy for fibrotic lung disease.
\end{abstract}

Keywords: fibroblast; fibrogenesis; microarray; pulmonary fibrosis; transforming growth factor- $\beta$ Tohoku J. Exp. Med., 2014 August, 233 (4), 283-293. C 2014 Tohoku University Medical Press

\section{Introduction}

Idiopathic pulmonary fibrosis (IPF) is defined as a specific form of chronic, progressive fibrosing interstitial pneumonia of unknown cause characterized by a progressive worsening of dyspnea and lung function associated with a poor prognosis (Raghu et al. 2011). The fibrotic zones are composed mainly of dense collagen fibers, although scattered convex subepithelial foci of proliferating fibroblasts and myofibroblasts (i.e. so-called fibroblastic foci) are a consistent finding (King et al. 2001). And the fibroblastic foci burden found in lung biopsy samples is inversely correlated with lung fibrosis progression (Eickelberg et al. 1999). Lung myofibroblasts are characterized by a spindleshaped or stellate morphology with intra-cytoplasmic stress fibers, and by the expression of various mesenchymal markers, including alpha-smooth muscle actin ( $\alpha$-SMA), which is the most reliable marker of differentiation to myofibroblasts (Hu et al. 2003; Honda et al. 2013).

Transforming growth factor (TGF) $-\beta$ is a strong activator of myofibroblasts and is known to be a potent fibrotic growth factor (Honda et al. 2013). TGF- $\beta$ induces mitogenesis and chemotaxis in fibroblasts and promotes the accumulation of extra cellular matrix proteins by inducing the differentiation into myofibroblasts with regard to the lung fibrotic process (Kotani et al. 2008).

Cyclosporine is commonly utilized as an immunosuppressive drug, particularly for the prevention of acute allograft rejection (Flechner et al. 2008). It is a potent immunosuppressive agent which acts by binding to the

Received March 4, 2014; revised and accepted July 4, 2014. Published online August 13, 2014; doi: 10.1620/tjem.233.283.

Correspondence: Nao Hirota, M.D., Department of Respiratory Medicine, Toho University Omori Medical Center, 6-11-1 Omori-nishi,

Ota-ku, Tokyo 143-8541, Japan.

e-mail: 300930hn@med.toho-u.ac.jp 
cytosolic protein cyclophilin in immunocompetent lymphocytes, thereby inhibiting calcineurin, which dephosphorylates the nuclear factor of activated T-lymphocytes (NF$\mathrm{AT})$. As a result, there is a decrease in the activity of genes coding for Interleukin (IL)-2 and related cytokines, which in turn interferes with the function of effector T-cells by an inhibition of both lymphokine and interleukin production (Schreiber and Crabtree 1992; Ho et al. 1996). Cyclosporine also decreases TGF- $\beta 1$ expression in selfreactive T-cells by blocking NF-AT response elements in the TGF- $\beta 1$ promoter (Nakano et al. 2007). Recent evidence has also shown that cyclosporine can effectively reduce the inflammatory response by targeting the leukocyte recruitment mediated by extracellular cyclophilins in airway inflammation (Balsley et al. 2010).

Cyclosporine has been reported to be effective not only for interstitial pneumonias associated with collagen vascular diseases through a suppression of immune activity of lymphocytes (Nagasaka et al. 2003; Homma et al. 2005), but also for IPF and/or acute exacerbation of IPF (Lok et al. 1998; Inase et al. 2003; Piot et al. 2008; Sakamoto et al. 2010). In addition, certain novel functions of cyclosporine have been reported, including the reduction in infarct size in cases of acute myocardial infarction (Faul et al. 2008) and an anti-protein uric effect from which is derived the maintenance of synaptopodin protein level in podocytes (Akool et al. 2008). Effects have also been reported in renal epithelial cells by an activation of TGF- $\beta /$ Smad signaling in cultured mesangial cells (King et al. 2011) or an induction of the epithelial-mesenchymal transition in renal proximal tubular epithelial cells.

We investigated the effect of cyclosporine on human lung fibroblasts in vitro with regard to counter actions of TGF- $\beta$ by profiling gene expression using microarray analysis.

\section{Methods}

Reagents

The compound of cyclosporine was provided by Novartis Pharmaceuticals (Basel, Switzerland). The solution form of cyclosporine was diluted in $1 \mathrm{ml}$ sterile Dulbecco's Modified Eagle Medium (DMEM) containing $0.02 \mathrm{ml}$ Tween 80 and $0.1 \mathrm{ml}$ ethanol to make a stock solution, which was then further diluted into an appropriate concentration with DMEM for use in experiments.

\section{Cell culture and treatment}

The human fetal lung fibroblast cell line (MRC5) was purchased from Health Science Research Resources Bank (Tokyo, Japan). The cells were maintained in tissue culture $75 \mathrm{~cm}^{2}$ flasks (Falcon, Switzerland) in DMEM supplemented with $10 \% \mathrm{FBS}$ at $37^{\circ} \mathrm{C}$ in a humidified atmosphere containing $95 \%$ air and $5 \% \mathrm{CO}_{2}$. Cells were used between the $3 \mathrm{rd}$ and 5 th passage. Cells were seeded at $5 \times 10^{4}$ cells $/ \mathrm{ml}$ placed into $100 \mathrm{~mm}$ tissue culture plate (Falcon) 24 hours before treatment resulting in less than $70 \%$ confluency at treatment. After 24 hours serum starvation, fibroblasts were reacted with TGF- $\beta$ ( $3 \mathrm{ng} / \mathrm{ml}, \mathrm{R} \& \mathrm{D}$ Systems, UK) with or without cyclosporine $(2 \mu \mathrm{g} / \mathrm{ml})$. The effects were examined at 48 hours after treatment. In all experi- ments with cyclosporine, control cells were exposed to an appropriate concentration of vehicle described above. No antibiotics or antimycotics were added to culture media at any time.

\section{Protein immunoblotting}

Cells were seeded at $5 \times 10^{4}$ cells $/ \mathrm{ml}$ placed into 6 -well plate in DMEM with $10 \%$ FBS 24 hours before treatment resulting in less than $70 \%$ confluency at treatment. After 24 hours serum starvation, fibroblasts were reacted with TGF- $\beta(3 \mathrm{ng} / \mathrm{ml})$ with or without cyclosporine $(2 \mu \mathrm{g} / \mathrm{ml})$. The effects were examined at 48 hours after treatment. At the end of the incubation, the monolayer cell was washed twice with ice-cold PBS and cell-lysis was performed by adding radio-immunoprecipitation assay (RIPA) buffer and scraping with a rubber policeman. Protein lysates were resolved by electrophoresis in $12 \%$ SDS polyacrylamide gels and transferred electrophoretically to polyvinylidene difluoride (PVDF) membranes. Membranes were immunoblotted using the primary antibodies to $\alpha$-SMA (clone 1A4, SIGMA), or $\beta$-actin (clone AC-15, Sigma-Aldrich) with horseradish peroxidase-conjugated secondary antibodies. The blots were developed with an ECL chemiluminescent system (GE Healthcare BioSciences, Piscataway, NJ) and were analyzed for the relative amounts of proteins using Multi Gauge Ver3.0 software (FUJIFILM, Japan). Quantification was performed by measuring the intensity of the signals with the use of NIH Image analysis software.

Real-time quantitative reverse transcription-polymerase chain reaction

Total RNA was isolated from homogenized fibroblast cultures using RNeasy, according to the manufacturer's protocol (Qiagen, Valencia CA). RNA samples were DNase-treated and reverse-transcribed. Quantitative reverse transcription-polymerase chain reaction (qRT-PCR) was conducted with ABI prism 7500 (Applied Biosystems, Foster City, CA). PCR was performed using Power SYBR Green PCR Master Mix (Applied Biosystems). Results were normalized to $G A P D H$. Each sample was tested in triplicate. Fluorescence emission was detected for each PCR cycle and the threshold cycle values were determined. The primer sequences were as follows: ACTA2 sense, 5'-GACAATGGCTCTGGGCTCTGT AA-3'; ACTA2 anti-sense, 5'-CTGTGCTTCGTCACCCACGTA-3'; COL1A2 sense, 5'-AGATGGTGAAGATGGTCCCACAG-3'; COL1A2 anti-sense, 5'-TCCAGGGCCAAGTCCAACTC-3'; GAPDH sense, 5'-GCACCGTCAAGGCTGAGAAC-3'; GAPDH anti-sense, 5'-TGGTGAAGACGCCAGTGGA-3'; IGFBP2 sense, 5'-AGC CCAAGAAGCTGCGACCAC-3'; IGFBP2 anti-sense, 5'-CTGCCC GTTCAGAGACATCTTGC-3'; ID 1 sense, 5'-GTAAACGTG CTGCTCTACGACATGA-3'; IDI anti-sense, 5'-AGCTCCAACTGA AGGTCCCTGA-3'; PPARG sense, 5'-TGGAATTAGATGACA GCGACTTGG-3'; PPARG anti-sense, 5'-CTGGAGCAGCTTGGC AAACA-3'.

\section{Immunofluorescence}

Cells were seeded at $1 \times 10^{5}$ cells per well in DMEM $+10 \%$ fetal bovine serum on two chamber slides (Labtek, Nunc, Fisher Scientific UK, Ltd), grown to be subconfluent and quiescent in serumfree DMEM for 24 hours and exposed to TGF- $\beta$ and cyclosporine for 48 hours. The cells were gently washed three times with PBS, fixed for 20 minutes with $100 \%$ methanol at $-20^{\circ} \mathrm{C}$. The specific mouse monoclonal antibody against $\alpha$-SMA (1:1,000 dilution) were added overnight at $4^{\circ} \mathrm{C}$. Then these incubated cells for 24 hours were 
washed three times in PBS $+3 \%$ BSA before the specific Alexa Fluor 488 goat anti-mouse conjugate (1:1,000 dilution) and DAPI $(1: 10,000$ dilution), were added for 1 hour at room temperature.

\section{Microarray gene expression analysis}

Total RNA was isolated from MRC5 cells by using the RNeasy Mini kit (QIAGEN, Valencia, CA), and its quality was assessed by using an Agilent 2100 Bioanalyzer (Agilent Technologies, Palo Alto, CA). Total RNA was amplified and labeled according to manufacturer's instructions using the One-Color Low RNA Input Linear Amplification Kit Plus (Agilent Technologies). Labeling reaction input for all samples was $1 \mu \mathrm{g}$ of total RNA. This approach uses a T7 RNA polymerase which simultaneously amplifies the target material and incorporates cyanine 3-labeled CTP (Cy3-CTP). Samples were purified and quantified to obtain the yield of cRNA and specific activity of the $\mathrm{Cy} 3$ incorporation. Samples with an amplified yield of less than $1.65 \mu \mathrm{g}$ or a specific activity of less than 9 pmol Cy3 per $1 \mu \mathrm{g}$ cRNA were not hybridized to an array. For samples meeting these criteria, $1.65 \mu \mathrm{g}$ of labeled cRNA was fragmented and suspended in hybridization buffer and hybridized onto one array of an Agilent $4 \times$ 44K Whole Human Genome Oligo microarray slide. Samples were placed in Agilent G2545A hybridization oven at $65^{\circ} \mathrm{C}$ for 17 hours with $10 \mathrm{rpm}$ rotation and were subsequently washed in Agilent Gene Expression Wash Buffers. Slides were then scanned on an Agilent G2565AA Microarray Scanner using the extended dynamic range scanning mode at a $5 \mu \mathrm{m}$ resolution. Data were extracted from the images using Agilent Technologies' Feature Extraction software version 9.5.3.

\section{Microarray data normalization, filtering, and statistical analyses}

Gene expression data were analyzed using GeneSpring GX11 (Agilent Technologies). All data preprocessing and normalization were preformed according to manufacture and literature recommendations for optimal performance of the Agilent one-color array platform (Agilent Technologies). Normalization of the data was performed in GeneSpring GX11 as follows: values below 5.0 were set to 5.0, a per chip normalization to the 50th percentile value, and a per gene normalization to the median value in all samples. Prior to statistical analysis, data were prefiltered on flags (present, marginal or absent) and expression levels in order to focus the downstream analysis on the most reproducibly detectable measurements. For statistical analyses we applied significance analysis of microarrays (SAM). A $p$-value which corresponds to a user-defined false discovery rate of $5 \%$ was used as a cutoff of statistical significance in microarray. All data functional annotation was also performed in GeneSpringGX11. Pathway analysis was performed with the program Database for Annotation, Visualization, and Integrated Discovery (DAVID) 6.7 (http://david.abcc.ncifcrf.gov). The full complement of the expression data is available at Gene Expression Omnibus (GEO; http:// www.ncbi.nlm.nih.gov/geo; accession number GSE25200).

\section{Statistical analysis}

All data are expressed as means \pm significant difference (s.D.). Comparisons between two experimental groups were using a twotailed Student's unpaired $t$-test. Comparisons among three or more experimental groups were performed with non-repeated measures ANOVA with post hoc Bonferroni correction.

\section{Results}

Cyclosporine reduces $\alpha$-SMA and collagen I expression by myofibroblasts

A human fetal lung fibroblast cell line, MRC5, was starved for 24 hours to avoid the initial effects of endogenous TGF- $\beta$, various growth factors or cytokines contained in the serum. After TGF- $\beta(3 \mathrm{ng} / \mathrm{ml})$ and Cyclosporine $(0.25-16 \mu \mathrm{g} / \mathrm{ml})$ was added to the culture medium and incubated for 48 hours, the expression of $\alpha$-SMA was detected by Western blotting (Fig. 1A). The highest $\alpha$-SMA signal intensity was observed with TGF- $\beta(3 \mathrm{ng} / \mathrm{ml})$ only, and additional Cyclosporine prevented the expression of $\alpha$-SMA in a dose-dependent manner. A western blot representative of three independent experiments is shown. Similar results were observed by quantitative analysis using real time RT-PCR, which showed that TGF- $\beta$ induced $\alpha$-SMA (gene symbol: ACTA2) mRNA expression was significantly decreased by $2 \mu \mathrm{g} / \mathrm{ml}$ or more of cyclosporine (Fig. 1B). Based on these findings of a pilot study, and also considering the clinical dose of cyclosporine, we adopted $2 \mu \mathrm{g} / \mathrm{ml}$ of cyclosporine for these experiments. We also examined the gene expression of collagen type I, another marker of differentiated myofibroblasts, the expression level of collagen, type I, alpha 2 (gene symbol: COL1A2) mRNA was increased 5.2 fold by TGF- $\beta$ in comparison with control, whereas the expression level in the TGF- $\beta$ plus cyclosporine-group was 2.5 fold decreased compared with the TGF$\beta$-group, significant for both groups (Fig. 2A). These alterations in immunoreactivity were also observed by immunofluorescent staining of MRC5 in the control medium, with TGF- $\beta$ alone, and with TGF- $\beta$ and cyclosporine. The immunoexpression of $\alpha$-SMA was markedly increased by TGF- $\beta$ stimulation, and this effect was reduced by the addition of cyclosporine, in spite of the cell viability remaining apparently unaltered (Fig. 2B). These results indicate that the differentiation of fibroblasts into myofibroblasts and the synthesis of collagen by myofibroblasts were both prevented by cyclosporine.

Gene profiling of the anti-fibrogenesis effect of cyclosporine

We employed a microarray technique to elucidate the changes in gene-expression in TGF- $\beta$-induced fibrogenesis by cyclosporine in lung fibroblast culture cells. An original total of 41078 genes was reduced to 26686 genes after quality control along with the GeneSpring GX11 algorithm, and finally a two-fold variation was detected in 2111 genes between the control and TGF- $\beta$ treated cells, and 886 genes between the TGF- $\beta$ and TGF- $\beta$ plus cyclosporine treated cells. Of these 2111 genes, 871 genes were up-regulated by TGF- $\beta$, and of these, 57 genes were recovered by cyclosporine treatment. Of the 2111 differently expressed genes, 1240 genes were down-regulated in expression level by TGF- $\beta$, and of these, 73 genes were recovered by cyclosporine treatment. Thus, the expression of $130(57+73)$ genes were selected. These results are summarized in a Venn dia- 
A
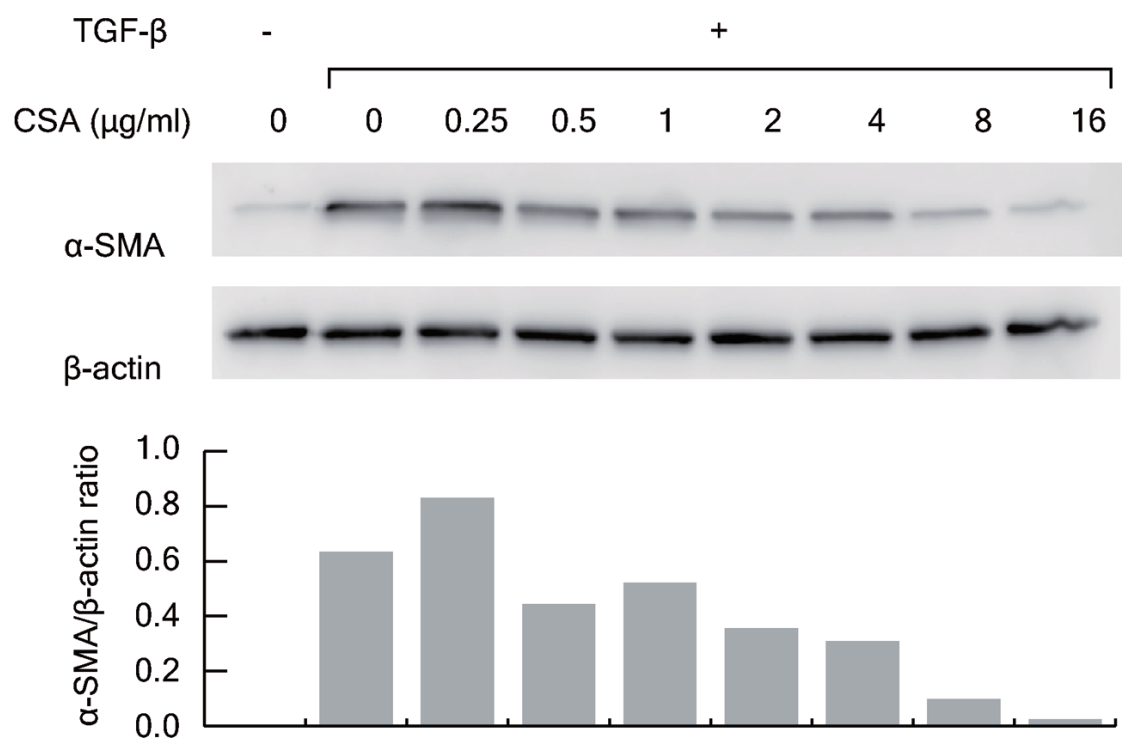

B

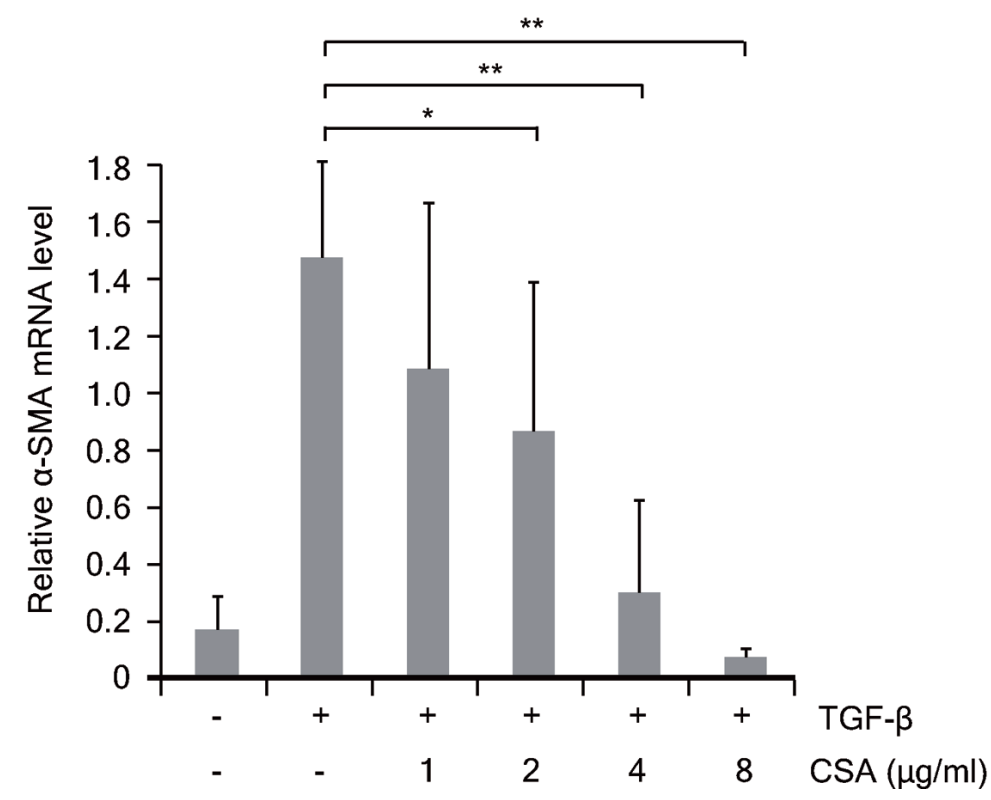

Fig. 1. Cyclosporine inhibited differentiation of fibroblasts into myofibroblasts.

A: Western blot showing cyclosporine suppressed $\alpha$-SMA induction by TGF- $\beta$ in a dose-dependent manner. Bar chart represents results of semi-quantitative densitometric analysis of the $\alpha$-SMA signal expressed as arbitrary units and which were normalized to $\beta$-actin.

B: The relative levels of the mRNA of ACTA2, normalized by GAPDH, were also down-regulated by cyclosporine. Data represent the means \pm S.D. of three independent experiments $\left({ }^{*} p<0.05,{ }^{* *} p<0.01\right)$. CSA, cyclosporine.

gram to depict the result simply, and to indicate the genes that had an opposing effect on TGF- $\beta$ (Fig. 3).

Direct comparison of the gene expression is shown (Fig. 4A) in the scatter plots of the control and TGF- $\beta$ treatment groups (left) and the TGF- $\beta$ and TGF- $\beta$ plus cyclosporine groups (right). The green lines indicate a two folds alteration between the groups. The profile plots (Fig. 4B) show the more than two fold alterations in gene expression among the control, TGF- $\beta$ and TGF- $\beta$ plus cyclosporine groups. To assess the biological processes in which these 130 genes were involved, we analyzed and grouped them according to their biological function using the GeneSpring Annotation tool. The results revealed that 41 out of the 57 genes which were up-regulated by TGF- $\beta$ and lowered by cyclosporine were annotated in the Genetic Ontology (GO) biological processes (Table 1). On the second branch of 
A

ACTA2

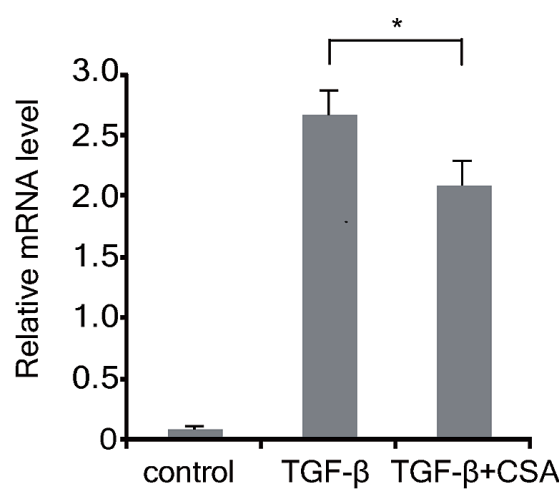

COL $1 A 2$

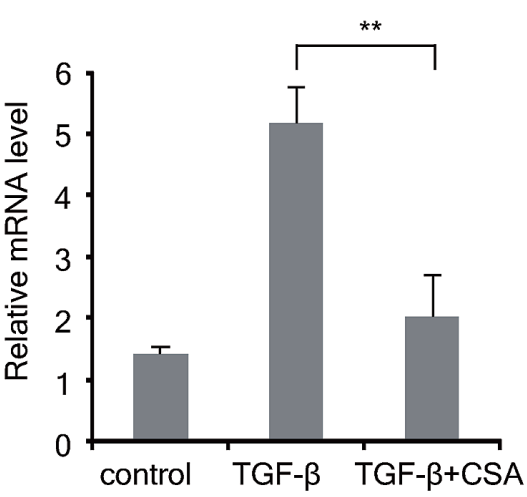

B

control

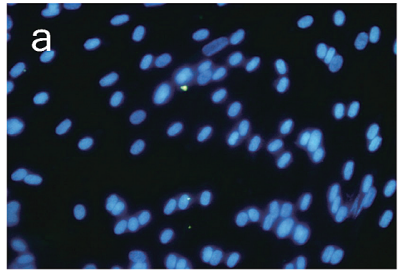

TGF- $\beta$

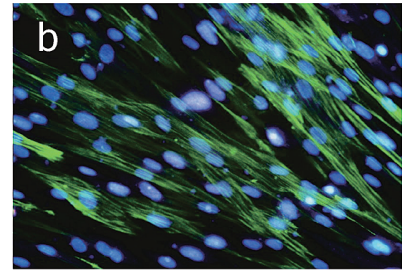

TGF $-\beta+C S A$

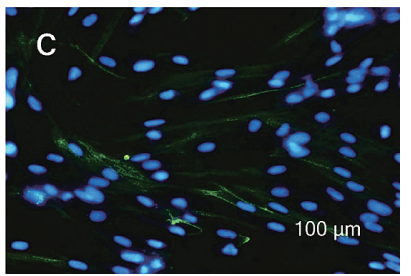

Fig. 2. Cyclosporine reduces collagen-I and $\alpha$-SMA expression, as confirmed by real-time PCR and immunofluorescent staining.

A: The relative levels of the mRNA of $A C T A 2$ and COL1A2, normalized with GAPDH mRNA, were lowered by cyclosporine. Data represent the means \pm S.D. of three independent experiments.

B: Immunofluorescent staining showed that the immuno-expression of $\alpha$-SMA (in green) was suppressed by cyclosporine (magnification at $\times 400$ ). The images are representative of a minimum of 15 fields viewed for the three separate experiments. CSA, cyclosporine.

Statistical analysis; $\mathrm{P}<0.01$

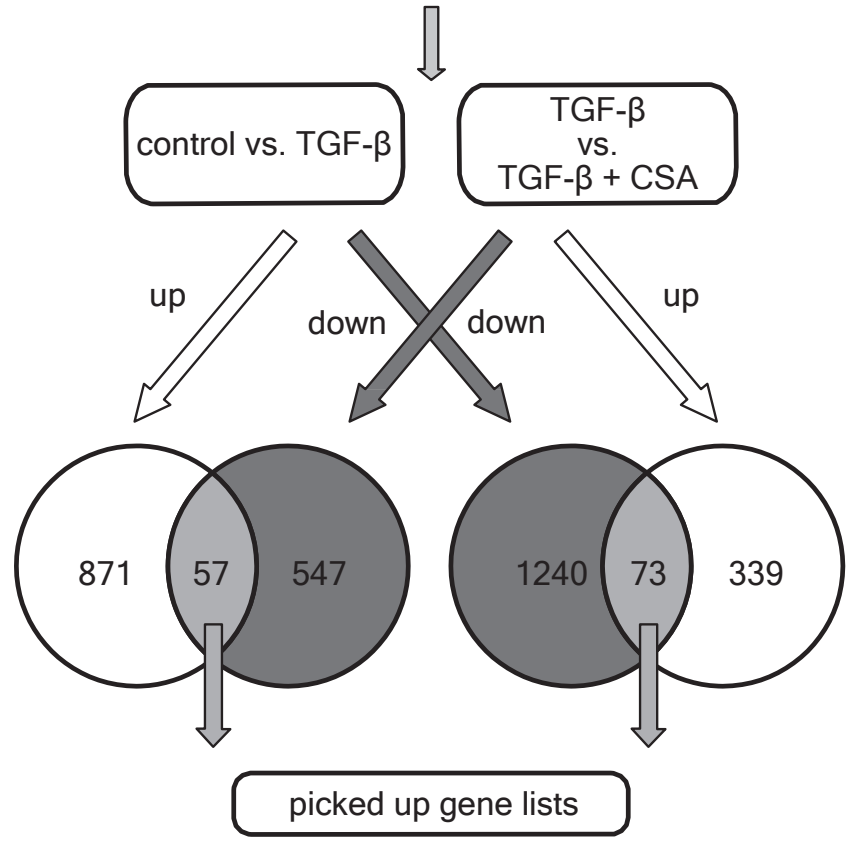

Fig. 3. Flow chart of experimental design for gene profiling. CSA, cyclosporine.
$\mathrm{GO}, 31$ out of these 41 genes were shown to be involved in signal transduction, six in organ morphogenesis and four in response to mechanical stimulus. On the other hand, 25 out of the 73 genes which were down-regulated by TGF- $\beta$ and restored by cyclosporine were annotated in the GO biological processes, and 16 genes were found to be involved in signal transduction, eight in organ morphogenesis and one was in mechanical stimulus (Table 2).

\section{Pathway analysis of the altered genes}

Finally, to determine the significantly regulated pathways, the genes obtained in our experiments were mapped to the Kyoto Encyclopedia of Genes and Genomes (KEGG) pathways (Table 3). The obtained genes were uploaded to the DAVID website, where the DAVID beta 6.7 functional annotation tool identified the KEGG pathways showing an enrichment for these genes and the probability of that pathway being significantly altered. Fisher's exact test (maximum probability 0.1 ) was used to determine the enrichment probability. Output charts were obtained for the distribution of the significantly expressed genes in these KEGG pathways. Marked changes in expression levels were seen for five gene sets in the NOD-like receptor signaling pathway (BIRC3, CCL2, CXCL1, CXCL2, TNFAIP3), eight in 
A

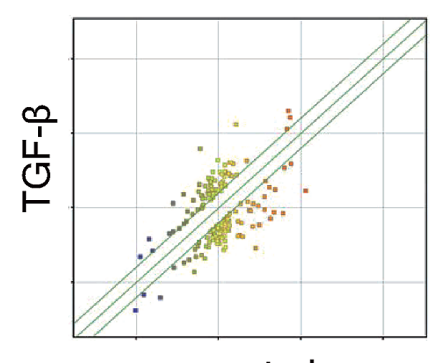

control

B

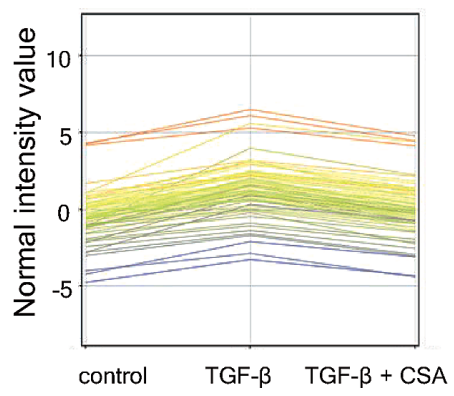

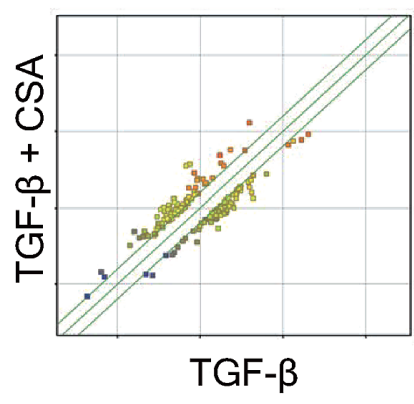

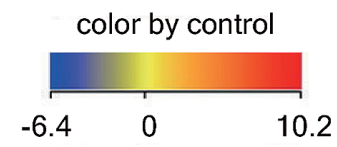

TGF- $\beta$
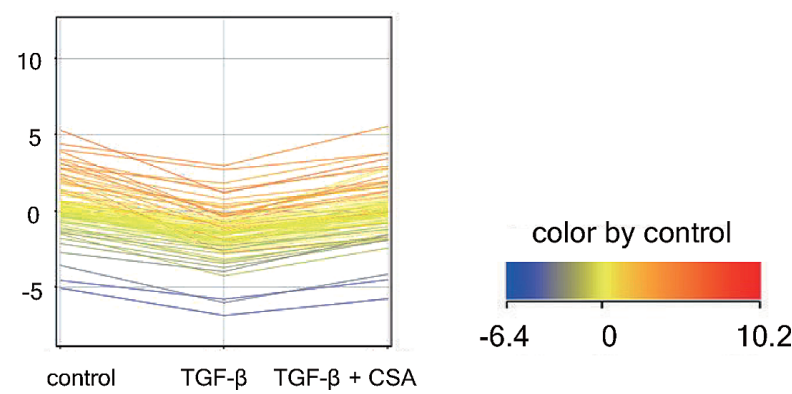

Fig. 4. The results of microarray gene profiling.

A: Direct comparison of gene expression between the control (left; horizontal axis) and TGF- $\beta$ group (left; vertical axis) by scatter plot. TGF- $\beta$ (right; horizontal axis) and TGF- $\beta$ plus cyclosporine group (right; vertical axis). The scatter plot displays the normalized intensity values of each entity. Three green lines indicate two-fold (upper), zero (middle) and one second (bottom) change between the groups.

B: The profile plot shows two fold changes in gene expression between the control, TGF- $\beta$ and TGF- $\beta$ plus cyclosporine exposed cells (left to right). Each continuous line corresponds to a single probe sets normalized log ratio intensity value (y-axis) for each condition (x-axis). Data are normalized and baseline transformed to center values around a baseline of zero. Therefore, normalized values of zero represents baseline level of probe intensity values, values greater than zero represent up-regulated probes, and values less than zero represent down-regulated probes. CSA, cyclosporine.

Table 1. GO terms related to selected genes.

\begin{tabular}{clccc}
\hline GO ACCESSION & \multicolumn{1}{c}{ GO Term } & corrected $p$-value & Count in Selection & \% Count in Selection \\
\hline GO:0007154 & cell communication & $3.94 \mathrm{E}-04$ & 26 & 70.3 \\
GO:0007165 & signal transduction & $4.96 \mathrm{E}-03$ & 25 & 67.6 \\
GO:0044421 & extracellular region part & $5.39 \mathrm{E}-03$ & 16 & 43.2 \\
GO:0009887 & organ morphogenesis & $5.39 \mathrm{E}-03$ & 8 & 21.6 \\
GO:0032502 & developmental process & $1.13 \mathrm{E}-02$ & 8 & 21.6 \\
GO:0005615 & extracellular space & $2.87 \mathrm{E}-02$ & 16 & 43.2 \\
GO:0009612 & response to mechanical stimulus & $4.12 \mathrm{E}-02$ & 3 & 8.1 \\
\hline
\end{tabular}

Gray lines; 3rd level of GO biological process (see Table 2).

cytokine-cytokine receptor interactions (KITLG, BMP2, CCL2, CXCL1, CXCL2, IL18r1, TSLP, TNFSF15), four in the TGF- $\beta$ signaling pathway (BMP2, ID1, ID4, PITX2) and seven in the cancer pathway (KITLG, BIRC3, BMP2, FGF13, IGF1, PPARG, WNT9A) (Table 3).

\section{Microarray data validation}

Validation of the microarray data on the selected genes was performed by real time PCR using RNA from three distinct cell cultures. We found a similar pattern of expres- sion of the genes encoding IGFBP2, IDI and PPARG (Fig. $5)$. All of these expression pattern variations were statistically significant.

\section{Discussion}

We showed the direct anti-fibrotic effect of cyclosporine on human lung myofibroblasts, which is an unexplained phenomenon through an immunosuppression of activated lymphocytes. Myofibroblasts comprise the predominant fibroblast phenotype in the cells that are present 
Table 2. Details of selected GO terms.

A. Signal transduction.

\begin{tabular}{|c|c|c|c|c|}
\hline Probe Name & Gene Symbol & Description & $\begin{array}{l}\text { control vs. TGF } \\
\text { (fold change) }\end{array}$ & $\begin{array}{c}\text { TGF vs. } \\
\text { TGF + CSA } \\
\text { (fold change) }\end{array}$ \\
\hline A_23_P13907 & $I G F 1$ & insulin-like growth factor 1 (somatomedin C) (IGF1) & 34.54 & 0.29 \\
\hline A_23_P153676 & $T L E 2$ & transducin-like enhancer of split 2 (E(sp1) homolog, Drosophila) (TLE2) & 8.62 & 0.47 \\
\hline A_23_P254654 & CLIC3 & chloride intracellular channel 3 (CLIC3) & 6.83 & 0.30 \\
\hline A_23_P146444 & CORO2A & coronin, actin binding protein, $2 \mathrm{~A}(\mathrm{CORO} 2 \mathrm{~A})$ & 5.16 & 0.40 \\
\hline A_24_P51127 & $W N K 1$ & WNK lysine deficient protein kinase 1 & 4.91 & 0.29 \\
\hline A_23_P64611 & $P 2 R Y 6$ & pyrimidinergic receptor P2Y, G-protein coupled, 6 (P2RY6) & 3.92 & 0.46 \\
\hline A_23_P27734 & NPAS1 & neuronal PAS domain protein 1 (NPAS1) & 3.26 & 0.47 \\
\hline A_23_P252306 & ID1 & $\begin{array}{l}\text { inhibitor of DNA binding 1, dominant negative helix-loop-helix protein } \\
\text { (ID1) }\end{array}$ & 3.20 & 0.43 \\
\hline A_23_P45424 & $I T G B 1 B P 2$ & integrin beta 1 binding protein (melusin) 2 (ITGB1BP2) & 2.90 & 0.38 \\
\hline A_23_P58321 & CCNA2 & cyclin A2 (CCNA2) & 2.50 & 0.33 \\
\hline A_23_P135061 & CORO2A & coronin, actin binding protein, 2A (CORO2A) & 2.44 & 0.49 \\
\hline A_23_P108265 & OR7C2 & olfactory receptor, family 7, subfamily C, member 2 (OR7C2) & 2.42 & 0.19 \\
\hline A_23_P258381 & $S P S B 4$ & splA/ryanodine receptor domain and SOCS box containing 4 (SPSB4) & 2.33 & 0.48 \\
\hline A_23_P378329 & WNT9A & wingless-type MMTV integration site family, member 9A & 2.24 & 0.48 \\
\hline A_23_P161352 & PTPLA & $\begin{array}{l}\text { protein tyrosine phosphatase-like (proline instead of catalytic arginine), } \\
\text { member A (PTPLA) }\end{array}$ & 2.10 & 0.46 \\
\hline A_23_P86561 & $C A L Y$ & calcyon neuron-specific vesicular protein (CALY) & 2.07 & 0.50 \\
\hline A_23_P42868 & $I G F B P 1$ & insulin-like growth factor binding protein 1 (IGFBP1) & 0.48 & 2.05 \\
\hline A_23_P167920 & $D L L 1$ & delta-like 1 (Drosophila) (DLL1) & 0.46 & 2.26 \\
\hline A_23_P159325 & ANGPTL4 & angiopoietin-like 4 (ANGPTL4) & 0.43 & 12.13 \\
\hline A_23_P206280 & GPR56 & G protein-coupled receptor 56 (GPR56) & 0.42 & 2.45 \\
\hline A_23_P315364 & $C X C L 2$ & chemokine (C-X-C motif) ligand 2 (CXCL2) & 0.42 & 5.41 \\
\hline A_23_P94754 & TNFSF 15 & tumor necrosis factor (ligand) superfamily, member 15 (TNFSF15) & 0.42 & 4.48 \\
\hline A_23_P155057 & CYTH4 & cytohesin 4 (CYTH4) & 0.41 & 2.71 \\
\hline A_23_P111311 & $A K A P 12$ & A kinase (PRKA) anchor protein 12 (AKAP12) & 0.40 & 2.14 \\
\hline A_23_P119943 & $I G F B P 2$ & insulin-like growth factor binding protein 2, 36 kDa (IGFBP2) & 0.39 & 2.29 \\
\hline A_23_P60811 & PRKAA2 & protein kinase, AMP-activated, alpha 2 catalytic subunit (PRKAA2) & 0.37 & 2.07 \\
\hline A_23_P140290 & RTN1 & reticulon $1(\mathrm{RTN} 1)$ & 0.37 & 2.68 \\
\hline A_24_P208567 & IL18R1 & interleukin 18 receptor 1 (IL18R1) & 0.35 & 2.65 \\
\hline A_23_P143331 & $B M P 2$ & bone morphogenetic protein 2 (BMP2) & 0.32 & 3.02 \\
\hline A_23_P61406 & SHC3 & $\begin{array}{l}\text { SHC (Src homology } 2 \text { domain containing) transforming protein } 3 \\
\text { (SHC3) }\end{array}$ & 0.32 & 2.54 \\
\hline A_32_P152437 & $A K A P 12$ & A kinase (PRKA) anchor protein 12 (AKAP12) & 0.30 & 2.46 \\
\hline A_32_P94160 & PRKAA2 & protein kinase, AMP-activated, alpha 2 catalytic subunit (PRKAA2) & 0.30 & 2.07 \\
\hline A_23_P29096 & PDE9A & phosphodiesterase 9A (PDE9A), transcript variant 1 & 0.28 & 2.12 \\
\hline A_24_P133253 & KITLG & KIT ligand (KITLG) & 0.25 & 2.37 \\
\hline A_23_P425681 & $C C K$ & cholecystokinin (CCK) & 0.25 & 2.26 \\
\hline A_23_P128215 & SOCS2 & suppressor of cytokine signaling 2 (SOCS2) & 0.23 & 2.53 \\
\hline A_23_P217319 & $F G F 13$ & fibroblast growth factor 13 (FGF13) & 0.23 & 2.32 \\
\hline A_24_P766204 & $M A P 3 K 1$ & mitogen-activated protein kinase kinase kinase 1 (MAP3K1) & 0.22 & 3.66 \\
\hline A_23_P7144 & $C X C L 1$ & $\begin{array}{l}\text { chemokine (C-X-C motif) ligand } 1 \text { (melanoma growth stimulating activ- } \\
\text { ity, alpha) (CXCL1) }\end{array}$ & 0.18 & 3.61 \\
\hline A_23_P98350 & $B I R C 3$ & baculoviral IAP repeat-containing 3 (BIRC3) & 0.18 & 3.68 \\
\hline A_23_P252062 & PPARG & peroxisome proliferator-activated receptor gamma (PPARG) & 0.17 & 2.77 \\
\hline A_24_P230675 & SOCS2 & suppressor of cytokine signaling 2 (SOCS2) & 0.15 & 3.58 \\
\hline A_23_P7752 & SEMA6A & $\begin{array}{l}\text { sema domain, transmembrane domain (TM), and cytoplasmic domain, } \\
\text { (semaphorin) 6A (SEMA6A) }\end{array}$ & 0.14 & 2.05 \\
\hline A_23_P29922 & $T L R 3$ & toll-like receptor 3 (TLR3) & 0.12 & 2.43 \\
\hline A_23_P89431 & CCL2 & chemokine (C-C motif) ligand 2 (CCL2) & 0.12 & 2.00 \\
\hline A_23_P200780 & $T G F B R 3$ & transforming growth factor, beta receptor III (TGFBR3) & 0.10 & 2.25 \\
\hline A_23_P27306 & COLEC12 & collectin sub-family member 12 (COLEC12) & 0.03 & 2.02 \\
\hline
\end{tabular}

CSA, cyclosporine. 
Table 2. Continued.

B. Organ morpohogenesis.

\begin{tabular}{lllrl}
\hline Probe Name & Gene Symbol & \multicolumn{1}{c}{ Description } & $\begin{array}{c}\text { control vs. TGF } \\
\text { (fold change) }\end{array}$ & $\begin{array}{c}\text { TGF vs. } \\
\text { TGF+CSA } \\
\text { (fold change) }\end{array}$ \\
\hline A_23_P13907 & IGF1 & insulin-like growth factor 1 (somatomedin C) (IGF1) & 34.54 \\
A_23_P205894 & ACTC1 & actin, alpha, cardiac muscle 1 (ACTC1) & 9.29 \\
A_23_P153676 & TLE2 & transducin-like enhancer of split 2 (E(sp1) homolog, Drosophila) (TLE2) & 9.69 & 8.62 \\
A_23_P167367 & PITX2 & paired-like homeodomain 2 (PITX2) & 5.32 \\
A_24_P365975 & COL8A2 & collagen, type VIII, alpha 2 (COL8A2) & 0.47 \\
A_23_P252306 & ID1 & inhibitor of DNA binding 1, dominant negative helix-loop-helix protein & 4.84 \\
A_23_P58321 & CCNA2 & cyclin A2 (CCNA2) & 3.20 \\
A_23_P17044 & SFTPB & surfactant protein B (SFTPB) & 0.47 \\
A_24_P184692 & NKX2-1 & NK2 homeobox 1 (NKX2-1) & 2.50 \\
A_23_P143331 & BMP2 & bone morphogenetic protein 2 (BMP2) & 2.12 \\
A_23_P252062 & PPARG & peroxisome proliferator-activated receptor gamma (PPARG) & 0.43 \\
A_23_P7752 & SEMA6A & sema domain, transmembrane domain (TM), and cytoplasmic domain, & 0.33 \\
A_23_P89431 & (semaphorin) 6A (SEMA6A) & chemokine (C-C motif) ligand 2 (CCL2) & 0.41 \\
A_23_P200780 & TGFBR3 & transforming growth factor, beta receptor III (TGFBR3) & 0.32 \\
\hline
\end{tabular}

CSA, cyclosporine.

C. Response to mechanical stimulus.

\begin{tabular}{|c|c|c|c|c|}
\hline Probe Name & Gene Symbol & Description & $\begin{array}{l}\text { control vs. TGF } \\
\text { (fold change) }\end{array}$ & $\begin{array}{c}\text { TGF vs. } \\
\text { TGF+ CSA } \\
\text { (fold change) }\end{array}$ \\
\hline A_23_P11806 & COL11A1 & collagen, type XI, alpha 1 (COL11A1) & 3.45 & 0.32 \\
\hline A_23_P119943 & $I G F B P 2$ & insulin-like growth factor binding protein 2, $36 \mathrm{kDa}$ (IGFBP2) & 0.39 & 2.29 \\
\hline A_23_P143331 & $B M P 2$ & bone morphogenetic protein 2 (BMP2) & 0.32 & 3.02 \\
\hline A_23_P89431 & CCL2 & chemokine (C-C motif) ligand 2 (CCL2) & 0.12 & 2.00 \\
\hline A_24_P235338 & TRPA1 & $\begin{array}{l}\text { transient receptor potential cation channel, subfamily A, member } 1 \\
\text { (TRPA1) }\end{array}$ & 0.05 & 6.28 \\
\hline
\end{tabular}

CSA, cyclosporine.

Table 3. List of KEGG pathway correspond to selected gene lists calculated by DAVID algorithm.

\begin{tabular}{clcc}
\hline Category & \multicolumn{1}{c}{ Term } & Count & $P$-value* \\
\hline hsa04621 & NOD-like receptor signaling pathway & 5 & 0.0026 \\
hsa04060 & Cytokine-cytokine receptor interaction & 8 & 0.0107 \\
hsa04350 & TGF-beta signaling pathway & 4 & 0.0482 \\
\hline
\end{tabular}

*All genes were included in terms that had EASE (modified Fisher exact $P$-value) scores of 0.1 or less.

within active fibrotic lesions in the lungs of IPF patients, and the acquisition of the myofibroblasts phenotype is thus thought to play a major role in excessive deposition of matrix proteins during the development of pulmonary fibrosis (Raghu et al. 2011). Clearly, understanding and controlling the phenomenon that the fibroblasts to myofibroblasts differentiation should provide insights into how to treat fibrotic lung disease. We used MRC5 (human normal fetal lung fibroblast cell line) as an in vitro model. To confirm the phenomenon that Cyclosporine suppresses fibroprolifer- ative effect of fibroblasts which is induced by the action of TGF- $\beta$, we used three different methods, immunoblotting, realtime-PCR and immunofluorescence. The $\alpha$-SMA expression was used as an indication of fibroblasts to myofibroblasts differentiation. And we added various concentration of Cyclosporine into the medium to evaluate how much in quantity the suppressive effect. From results by realtime-PCR, the effect was observed $2 \mu \mathrm{g} / \mathrm{ml}$ or more concentration of Cyclosporine. So we used $2 \mu \mathrm{g} / \mathrm{ml}$ concentration on the later experiments. It was previously 
IGFBP2

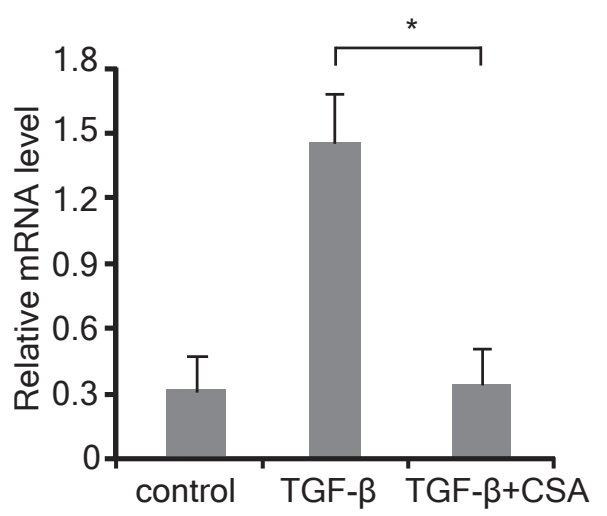

ID1

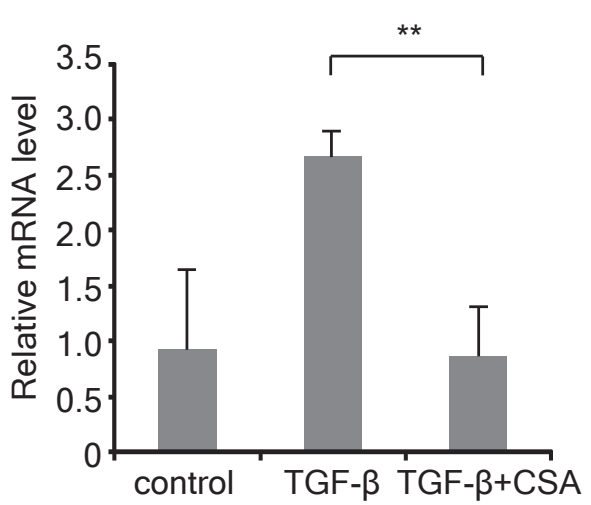

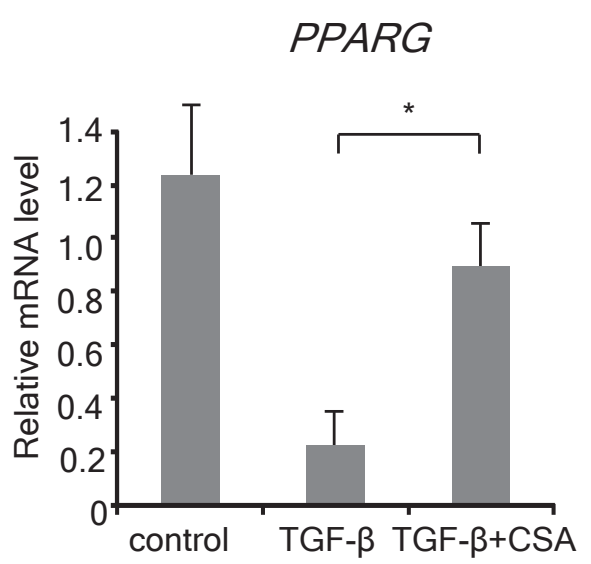

Fig. 5. Validation of microarray analysis by real-time PCR. Real-time PCR data were normalized to the expression level of the GAPDH mRNA. The same genes were tested in the three independent experiments $\left({ }^{*} p<0.05,{ }^{* *} p<0.01\right)$. CSA, cyclosporine.

reported that cyclosporine inhibits TGF- $\beta$-induced signaling and collagen deposition in lung fibroblasts, using proline incorporation assay (Eickelberg et al. 2001). Also, we have shown that cyclosporine suppresses the differentiation of fibroblasts into myofibroblasts in a concentration-dependent manner. These results support the hypothesis that cyclosporine has several potency for fibrotic lung disease by inhibition of collagen deposition but also suppression of the fibroblasts to myofibroblasts differentiation, which are expected to have another mechanisms independent from the activation of lymphocytes (Ebina et al. 2011).

We employed a microarray technique in this study to carry out gene-expression profiling in fibroblasts treated with TGF- $\beta$ and cyclosporine or without cyclosporine. Microarray analysis resulted in a variety of candidate genes potentially related to the anti-fibroproliferative effects of cyclosporine. In pathway analysis of selected genes by DAVID website, not TGFBR1 or TGFBR2 and its downstream genes as a major gene, but $B M P 2$ and its downstream genes such as ID1, ID4 or Nodal's downstream gene, PITX2, were altered in TGF- $\beta$ super family pathway. Furthermore, in particular, IGFI and its related genes were extracted from the analysis, while several growth factors are known to play a pivotal role in generating fibrotic lung disease. These genes may contribute to the development of lung fibrosis, particular in fibroblasts to myofibroblasts differentiation repressed by cyclosporine. However, it is necessary to clarify whether or not the phenomenon observed in the present study being depends on those pathways.

Many genes were obtained from the microarray analysis, we took an approach that so-called "Cherry picking" on gene selection as previous study (Kaminski and Rosas 2006). We choose three of them, IDI, IGFBP2, and PPARG. All of these independently have a role in the pathogenesis of fibrotic lung disease.

IDI encodes the DNA-binding protein inhibitor ID 1, a helix-loop-helix (bHLH) protein that lacks a basic region required for direct binding to DNA. It forms a heterodimer with DNA-binding basic HLA proteins of transcription factors and acts as a dominant negative inhibitor of basic HLH proteins that drive cell lineage commitment and differentiation (Benezra et al. 1990). In addition, ID 1 is induced by TGF- $\beta$ via the activation of MyoD and its interaction with TGF- $\beta$ (Chambers et al. 2003), a regulator of myogenic dif- 
ferentiation, which may be related to its effects on myofibroblast differentiation in the lung of IPF patients. Based on these findings, our results indicate that IDI is a one of the target gene of TGF- $\beta$ in fibroblasts that is reduced by cyclosporine.

IGFBP2 has been reported to be related to IPF in the lung tissues of patients (Ruan and Ying 2010). The concentration of IGFBP2 in bronchoalveolar lavage (BAL) fluid was significantly increased in IPF patients in comparison with normal controls and was significantly related to poor pulmonary function (Chadelat et al. 1998). Therefore, these results, which show a reduction of IGFBP 2 expression by cyclosporine, support a clinical effect against fibrogenesis in IPF.

Peroxisome proliferator-activated receptor gamma (PPARG) is one of three different isoforms of the PPARs, which is a transcription factor belonging to the nuclear hormone receptor family that is expressed in many types of pulmonary cells, including fibroblasts (Huang et al. 2005). The mechanisms of inhibition by PPARG agonists of TGF$\beta$-induced differentiation of human lung fibroblasts to myofibroblast might be caused by interference of the PPARG ligands with the Smad family (Burgess et al. 2005), could be the result of a direct activation of calcineurin by TGF- $\beta$, and in turn by direct suppression of cell growth and collagen production in hepatic stellate cells by cyclosporine (Zheng and Chen 2004). Both of these results support a direct effect of cyclosporine against fibroproliferation of myofibroblasts.

We used $2 \mu \mathrm{g} / \mathrm{ml}$ in current study to investigate the anti-fibrotic effects on myofibroblasts, because this concentration is clinical dose in treatment for rapid progressive interstitial pneumonia. Because a nephrotoxicity is the most famous and frequent adverse drug reaction of cyclosporine, the concentration in this study may cause undesirable effects in renal epithelial cells and proximal tubular epithelial cells. However the development of similar compound to cyclosporine which is specialized in anti-fibrotic effect enables us to resolve this problem.

In conclusion, the present study has shown that cyclosporine modulates fibrogenesis in lung myofibroblasts, and thus provides the possibility that cyclosporine may become a novel drug in the treatment of fibrotic lung disease in near future.

\section{Acknowledgments}

This work was supported in part by Grant-in-Aid for Scientific Research by Japan Society for the Promotion of Science to M.E. (no. 22390164) and by the Diffuse Lung Diseases Research Group from the Ministry of Health, Labor and Welfare of Japanese Government. We thank Dr. Toshihiro Nukiwa for continuous support and helpful discussion.

\section{Conflict of Interest}

The authors declare no conflict of interest.

\section{References}

Akool, el-S., Doller, A., Babelova, A., Tsalastra, W., Moreth, K., Schaefer, L., Pfeilschifter, J. \& Eberhardt, W. (2008) Molecular mechanisms of TGF beta receptor-triggered signaling cascades rapidly induced by the calcineurin inhibitors cyclosporin A and FK506. J. Immunol., 181, 2831-2845.

Balsley, M.A., Malesevic, M., Stemmy, E.J., Gigley, J., Jurjus, R.A., Herzog, D., Bukrinsky, M.I., Fischer, G. \& Constant, S.L. (2010) A cell-impermeable cyclosporine A derivative reduces pathology in a mouse model of allergic lung inflammation. J. Immunol., 185, 7663-7670.

Benezra, R., Davis, R.L., Lockshon, D., Turner, D.L. \& Weintraub, H. (1990) The protein Id: a negative regulator of helix-loophelix DNA binding proteins. Cell, 61, 49-59.

Burgess, H.A., Daugherty, L.E., Thatcher, T.H., Lakatos, H.F., Ray, D.M., Redonnet, M., Phipps, R.P. \& Sime, P.J. (2005) PPARgamma agonists inhibit TGF-beta induced pulmonary myofibroblast differentiation and collagen production: implications for therapy of lung fibrosis. Am. J. Physiol. Lung Cell. Mol. Physiol., 288, L1146-1153.

Chadelat, K., Boule, M., Corroyer, S., Fauroux, B., Delaisi, B., Tournier, G. \& Clement, A. (1998) Expression of insulin-like growth factors and their binding proteins by bronchoalveolar cells from children with and without interstitial lung disease. Eur. Respir. J., 11, 1329-1336.

Chambers, R.C., Leoni, P., Kaminski, N., Laurent, G.J. \& Heller, R.A. (2003) Global expression profiling of fibroblast responses to transforming growth factor-betal reveals the induction of inhibitor of differentiation-1 and provides evidence of smooth muscle cell phenotypic switching. Am. J. Pathol., 162, 533-546.

Ebina, M., Taniguchi, H., Miyasho, T., Yamada, S., Shibata, N., Ohta, H., Hisata, S., Ohkouchi, S., Tamada, T., Nishimura, H., Ishizaka, A., Maruyama, I., Okada, Y., Takashi, K. \& Nukiwa, T. (2011) Gradual increase of high mobility group protein b1 in the lungs after the onset of acute exacerbation of idiopathic pulmonary fibrosis. Pulm. Med., 2011, 916486.

Eickelberg, O., Kohler, E., Reichenberger, F., Bertschin, S., Woodtli, T., Erne, P., Perruchoud, A.P. \& Roth, M. (1999) Extracellular matrix deposition by primary human lung fibroblasts in response to TGF-betal and TGF-beta3. Am. J. Physiol., 276, L814-824.

Eickelberg, O., Pansky, A., Koehler, E., Bihl, M., Tamm, M., Hildebrand, P., Perruchoud, A.P., Kashgarian, M. \& Roth, M. (2001) Molecular mechanisms of TGF-(beta) antagonism by interferon (gamma) and cyclosporine A in lung fibroblasts. FASEB J., 15, 797-806.

Faul, C., Donnelly, M., Merscher-Gomez, S., Chang, Y.H., Franz, S., Delfgaauw, J., Chang, J.M., Choi, H.Y., Campbell, K.N., Kim, K., Reiser, J. \& Mundel, P. (2008) The actin cytoskeleton of kidney podocytes is a direct target of the antiproteinuric effect of cyclosporine A. Nat. Med., 14, 931-938.

Flechner, S.M., Kobashigawa, J. \& Klintmalm, G. (2008) Calcineurin inhibitor-sparing regimens in solid organ transplantation: focus on improving renal function and nephrotoxicity. Clin. Transplant., 22, 1-15.

Ho, S., Clipstone, N., Timmermann, L., Northrop, J., Graef, I., Fiorentino, D., Nourse, J. \& Crabtree, G.R. (1996) The mechanism of action of cyclosporin A and FK506. Clin. Immunol. Immunopathol., 80, S40-45.

Homma, S., Sakamoto, S., Kawabata, M., Kishi, K., Tsuboi, E., Motoi, N. \& Yoshimura, K. (2005) Cyclosporin treatment in steroid-resistant and acutely exacerbated interstitial pneumonia. Intern. Med., 44, 1144-1150.

Honda, E., Park, A.M., Yoshida, K., Tabuchi, M. \& Munakata, H. (2013) Myofibroblasts: Biochemical and proteomic approaches to fibrosis. Tohoku J. Exp. Med., 230, 67-73. 
Hu, B., Wu, Z. \& Phan, S.H. (2003) Smad3 mediates transforming growth factor-beta-induced alpha-smooth muscle actin expression. Am. J. Respir. Cell Mol. Biol., 29, 397-404.

Huang, T.H., Razmovski-Naumovski, V., Kota, B.P., Lin, D.S. \& Roufogalis, B.D. (2005) The pathophysiological function of peroxisome proliferator-activated receptor-gamma in lungrelated diseases. Respir. Res., 6, 102.

Inase, N., Sawada, M., Ohtani, Y., Miyake, S., Isogai, S., Sakashita, H., Miyazaki, Y. \& Yoshizawa, Y. (2003) Cyclosporin A followed by the treatment of acute exacerbation of idiopathic pulmonary fibrosis with corticosteroid. Intern. Med., 42, 565-570.

Kaminski, N. \& Rosas, I.O. (2006) Gene expression profiling as a window into idiopathic pulmonary fibrosis pathogenesis: can we identify the right target genes? Proc. Am. Thorac. Soc., 3, 339-344.

King, T.E. Jr., Pardo, A. \& Selman, M. (2011) Idiopathic pulmonary fibrosis. Lancet, 378, 1949-1961.

King, T.E. Jr., Schwarz, M.I., Brown, K., Tooze, J.A., Colby, T.V., Waldron, J.A. Jr., Flint, A., Thurlbeck, W. \& Cherniack, R.M. (2001) Idiopathic pulmonary fibrosis: relationship between histopathologic features and mortality. Am. J. Respir. Crit. Care Med., 164, 1025-1032.

Kotani, T., Makino, S., Takeuchi, T., Kagitani, M., Shoda, T., Hata, A., Tabushi, Y. \& Hanafusa, T. (2008) Early intervention with corticosteroids and cyclosporin A and 2-hour postdose blood concentration monitoring improves the prognosis of acute/ subacute interstitial pneumonia in dermatomyositis. J. Rheumatol., 35, 254-259.

Lok, S.S., Smith, E., Doran, H.M., Sawyer, R., Yonan, N. \& Egan, J.J. (1998) Idiopathic pulmonary fibrosis and cyclosporine: a lesson from single-lung transplantation. Chest, 114, 14781481 .
Nagasaka, K., Harigai, M., Tateishi, M., Hara, M., Yoshizawa, Y., Koike, T. \& Miyasaka, N. (2003) Efficacy of combination treatment with cyclosporin A and corticosteroids for acute interstitial pneumonitis associated with dermatomyositis. Mod. Rheumatol., 13, 231-238.

Nakano, N., Hosokawa, H., Kohyama, M. \& Hozumi, N. (2007) NF-AT-mediated expression of TGF-betal in tolerant T cells. J. Immunol., 178, 3067-3075.

Piot, C., Croisille, P., Staat, P., Thibault, H., Rioufol, G., Mewton, N., Elbelghiti, R., Cung, T.T., Bonnefoy, E., Angoulvant, D., Macia, C., Raczka, F., Sportouch, C., Gahide, G., Finet, G., et al. (2008) Effect of cyclosporine on reperfusion injury in acute myocardial infarction. N. Engl. J. Med., 359, 473-481.

Raghu, G., Collard, H.R., Egan, J.J., Martinez, F.J., Behr, J., Brown, K.K., Colby, T.V., Cordier, J.F., Flaherty, K.R., Lasky, J.A., Lynch, D.A., Ryu, J.H., Swigris, J.J., Wells, A.U., Ancochea, J., et al. (2011) An official ATS/ERS/JRS/ALAT statement: idiopathic pulmonary fibrosis: evidence-based guidelines for diagnosis and management. Am. J. Respir. Crit. Care Med., 183, 788-824.

Ruan, W. \& Ying, K. (2010) Abnormal expression of IGF-binding proteins, an initiating event in idiopathic pulmonary fibrosis? Pathol. Res. Pract., 206, 537-543.

Sakamoto, S., Homma, S., Miyamoto, A., Kurosaki, A., Fujii, T. \& Yoshimura, K. (2010) Cyclosporin A in the treatment of acute exacerbation of idiopathic pulmonary fibrosis. Intern. Med., 49, 109-115.

Schreiber, S.L. \& Crabtree, G.R. (1992) The mechanism of action of cyclosporin A and FK506. Immunol. Today, 13, 136-142.

Zheng, S. \& Chen, A. (2004) Activation of PPARgamma is required for curcumin to induce apoptosis and to inhibit the expression of extracellular matrix genes in hepatic stellate cells in vitro. Biochem. J., 384, 149-157. 